\title{
Traffic Condition and Emission Factor from Diesel Vehicles within the Kathmandu Valley
}

\author{
Enna Mool ${ }^{1,2}$, Prakash V. Bhave ${ }^{2 \dagger}$, Nita Khanal ${ }^{1}$, Rejina M. Byanju ${ }^{1}$, Sagar Adhikari², \\ Bhupendra Das ${ }^{1}$, Siva P. Puppala ${ }^{2 *}$ \\ ${ }^{1}$ Central Department of Environmental Science, Tribhuvan University, Kathmandu, Nepal \\ ${ }^{2}$ International Centre for Integrated Mountain Development (ICIMOD), Khumaltar, Lalitpur, Nepal
}

\begin{abstract}
Past research on air quality within the Kathmandu Valley indicates that diesel vehicles make a substantial contribution to the ambient pollution. Hence, it's important to identify cost-effective measures for reducing their emissions. As a first step, roadside observations of diesel vehicles were recorded between February and April 2017 at six locations: two on the ring road (RR), two inside the RR, and two on major arterial highways outside the RR. Out of all diesel vehicles observed ( $n=$ $12,039), 35 \%$ were emitting a visible plume of black smoke and hereafter are referred to as "superemitters". Of the 4,248 superemitters, $45 \%$ were buses of varying sizes, 34\% were large trucks, and 19\% were small pickups. Superemitters made up the largest fraction of diesel vehicle traffic on the RR $(43 \%-46 \%)$ but were also abundant inside the RR $(27 \%-29 \%)$, where human population and pollutant exposure is greatest. Upon developing a comprehensive understanding of the superemitting vehicle types and ownership, maintenance patterns and servicing costs were studied through a survey of vehicle owners, vehicle drivers, and local maintenance centers. The costs of general servicing ranged between USD 16 for tractors and USD 203 for construction vehicles depending on the size of the vehicle. Lastly, the effect of general servicing on emissions while idling was explored for a small sample of superemitters $(n=4) . \mathrm{PM}_{2.5}$ emissions reduced from $10.90 \mathrm{~g} \mathrm{~L}$ to $3.76 \mathrm{~g} \mathrm{~L}^{-1}$ and $\mathrm{BC}$ emissions reduced from $0.847 \mathrm{~g} \mathrm{~L}^{-1}$ to $0.596 \mathrm{~g} \mathrm{~L}^{-1}$ after servicing. Taken together, results from this roadside surveillance study and exploratory emission-measurement campaign provide preliminary evidence that a policy of mandatory, routine maintenance of a targeted subset of the diesel fleet can systematically reduce emissions and improve air quality in the Kathmandu Valley and other cities around the world that are facing similar problems.
\end{abstract}

Keywords: General servicing; Plume opacity; Tailpipe exhaust; Urban transportation; Roadside surveillance.

\section{INTRODUCTION}

Air pollution levels are extremely high in urban areas of low- and middle-income countries (LMIC), where they represent an enormous burden on public health. Extensive research has been conducted in the urban areas of LMIC in recent decades (Edgerton et al., 1999; Molina and Molina, 2004; Petkova et al., 2013; Wang et al., 2013; Sahu and Kota, 2017), but the pace of air quality improvement remains slow in many of those cities (Colbeck et al., 2010; Maji et al., 2015; Njoku et al., 2016). Among those cities, the Kathmandu Valley is one such highly polluted area in the

\footnotetext{
${ }^{\dagger}$ Now at North Carolina State University, Raleigh, NC, USA

* Corresponding author.

Tel.: +977-1-5275222; Fax: +977-1-5275238

E-mail address: SivaPraveen.Puppala@icimod.org
}

South Asian region (Parajuly, 2016; Mahapatra et al., 2019). Earlier, air quality studies were limited in scope, especially because of the absence of appropriate instruments for measurements in the valley. This had caused inaccurate quantification of the total pollution load. However, in recent years, high-quality measurements of air quality have been started to address this issue.

A recent study conducted by Mahapatra et al. (2019) indicates an increasing trend of aerosol loading within the Kathmandu Valley by approximately $50-60 \%$ in between 2000-2015. This high pollution load could be attributed to rapid population and vehicular growth along with the increase in the energy demands of the valley. At the same time, the diurnal and seasonal variations in the pollutants of the valley were strongly influenced by the changes in the vehicle fleet (Sharma et al., 2012). Meanwhile, few source apportionment studies pointed out that emissions from vehicles, brick kilns, residential combustion, waste/biomass burning and soil dust, were the major contributors to pollution in the valley (Stone et al., 2010, 2012; Kim et al., 2015; Sarkar et al., 2017; Shakya et al., 2017). All these 
recent studies suggest that vehicular emissions is one of the major contributing factors to the ambient air pollution throughout the year (Sarkar et al., 2017; Shakya et al., 2017). On top of this, vehicular traffic is growing most rapidly, and in the period 2006-2016, it rose at a rate of $17.94 \%$ (Department of Transport Management, 2017). In 2004 2005, particulate matter with an aerodynamic diameter of less than 10 microns $\left(\mathrm{PM}_{10}\right)$ from diesel vehicles contributed to about $27 \%$ of the valley's emissions (Gautam, 2006). This fraction increased to about $34 \%$ of the total $\mathrm{PM}_{10}$ emissions in 2015-2016 (Department of Environment, 2017).

Not all the diesel vehicles plying the roads of the Kathmandu Valley contributes for pollution; in fact, a small proportion of high-emission vehicles (about $25 \%$ of the total diesel vehicle fleet) contributed to half of the emissions (Ale and Nagarkoti, 2003; Zhang et al., 1995). The high-emission vehicles are responsible for increasing the deviation in the emission distribution, even though average emissions have decreased substantially (Bishop and Stedman, 2008). These high-emission vehicles can be referred to as "superemitters". Some previous studies have classified superemitter vehicles based on visual observations (McCormick et al., 2003), while others have differentiated them based on probability distributions (Subramanian et al., 2009).

To date, no study has specifically examined the composition and emission contribution of the superemitter vehicles among the entire diesel vehicle fleet in the Kathmandu Valley. Only limited studies on the characteristics of these vehicle fleets have been carried out. In 2014, a study was conducted through roadside observations and the manual count method in order to identify the different types of vehicles in the Kathmandu Valley (Ghimire and Shrestha, 2014). The study indicated that trucks, minitrucks and tankers predominated among the diesel vehicles (Ghimire and Shrestha, 2014). However, the study did not address the composition and fraction of the superemitter vehicles among the total diesel vehicle fleet in the valley. In this study, therefore, we have identified - in terms of vehicle type and vehicle owner - the contribution of the superemitter vehicles to pollution.

Given the significance of diesel vehicle emissions and their contribution to Kathmandu's air quality, it is important to understand the emission factors (EF) of individual vehicle types. To date, only one study has been conducted, and that too only on the EF of pollutants and the impact of general servicing of gasoline vehicles in the Kathmandu Valley during engine idling (Jayarathne et al., 2018). The study indicated that the EF of $\mathrm{PM}_{2.5}$ reduced by $92 \%$ after servicing (Jayarathne et al., 2018); however, the values for diesel vehicles remain unknown. The emissions $\left(\mathrm{PM}_{2.5}\right.$ and black carbon, BC) from diesel vehicles were higher than those from gasoline ones (Kirchstetter et al., 1999; Ban-Weiss et al., 2008), and so we initiated a pilot study to understand the EF of pollutants from diesel vehicles. The $\mathrm{PM}_{2.5}, \mathrm{BC}$, $\mathrm{CO}$ and $\mathrm{CO}_{2}$ EFs of different types of diesel vehicles were measured during idling, and we also tried to understand the influence of general servicing on the reduction of emissions from diesel vehicles.

Many initiatives have already sought to control emissions from diesel vehicles. One of these, the inspection of diesel vehicles, was ineffective (Ale and Nagarkoti, 2003; Faiz et al., 2006). There are still not enough efficient technologies and human resources to carry out efficient vehicle testing in the valley (Jha, 2001; Gurung, 2016). Recently, the head of the Department of Transport Management (DoTM) publicly acknowledged that the inspection and maintenance program in Kathmandu is non-functional (Gurung, 2016). However, it's clear that the controlling of emissions from vehicles, including superemitters, can be addressed by cost-effective (Bond and Sun, 2005; Bhandarkar, 2013). The emissions from diesel vehicles after servicing were low compared to the vehicles that had not been serviced (Larssen et al., 1997), and in the Kathmandu Valley, they reduced by $34-42 \%$ after servicing (Ale and Nagarkoti, 2003).

The present study, through roadside observations in the Kathmandu Valley, tries to understand the dominance of superemitter diesel vehicles with respect to vehicle types and vehicle owners. To our knowledge, it is the first study in Nepal and Kathmandu Valley that records, through measurements, the EFs from diesel vehicles and explores the impact of proper servicing on emissions. Earlier, numerous studies had been carried out to estimate the emission load of various pollutants from different vehicle types. These emission inventories were prepared using decades-old EFs from different countries (Shrestha and Malla, 1996; Shrestha et al., 2013; Ghimire and Shrestha, 2014; Bajracharya and Bhattarai, 2016). This created a huge uncertainty (in terms of overestimation or underestimation) in the emission inventory of the Kathmandu Valley (Sarkar et al., 2017; Mahapatra et al., 2019). A realistic and updated emission inventory of the vehicle fleet in the valley has yet to be developed and there is a strong need to develop it by incorporating local estimates to reflect the real scenario of the area (Mues et al., 2018; Mahapatra et al., 2019).

This study provides the initial inputs into preparing an emission inventory of these vehicles; this will also help quantify global emissions. Further, it will provide evidence so that informed decisions can be taken in controlling the ambient air pollution in the Kathmandu Valley. An important point is that the EF calculated for diesel vehicles in this study, and the impact of servicing, do not represent all the diesel vehicles in the valley. In this regard, larger, indepth studies have been conducted (Zhang et al., 1995), along with regular monitoring. However, our study provides a baseline value for future research calculation of EF of diesel vehicles in the valley during engine idling, along with data on the impact of servicing on the EFs of these vehicles. In the future, we propose to carry out a detailed study of the emissions from different types of vehicles during idling, and when moving uphill and downhill, which will represent all diesel vehicles and driving conditions prevalent in the valley.

\section{METHODS}

\section{Roadside Survey}

A prominent feature of the Kathmandu Valley roadway network is a $27-\mathrm{km}$-long ring road (RR); it encompasses the 
urban centers of Kathmandu and Lalitpur, and carries twoway traffic, with four lanes in each direction. Numerous arterial roads emanate outward from the RR, while the two main arteries carry traffic to and from Bhaktapur (Eastern Highway) and the Trishuli River Valley (Western Highway). A web of local and residential streets, and a few multi-lane collectors, lie within the RR (Fig. 1).
Our survey locations were selected to characterize the wide variety of diesel traffic found in and around Kathmandu. The sites included two on the RR (Ekantakuna and Chabahil), two inside the RR (Kuleshwor and Sorakhutte), and one on each of the main arterial highways outside the RR (Ghathaghar and Kalanki). The exact locations met three selection criteria: (i) free-flowing traffic; (ii) minimal road

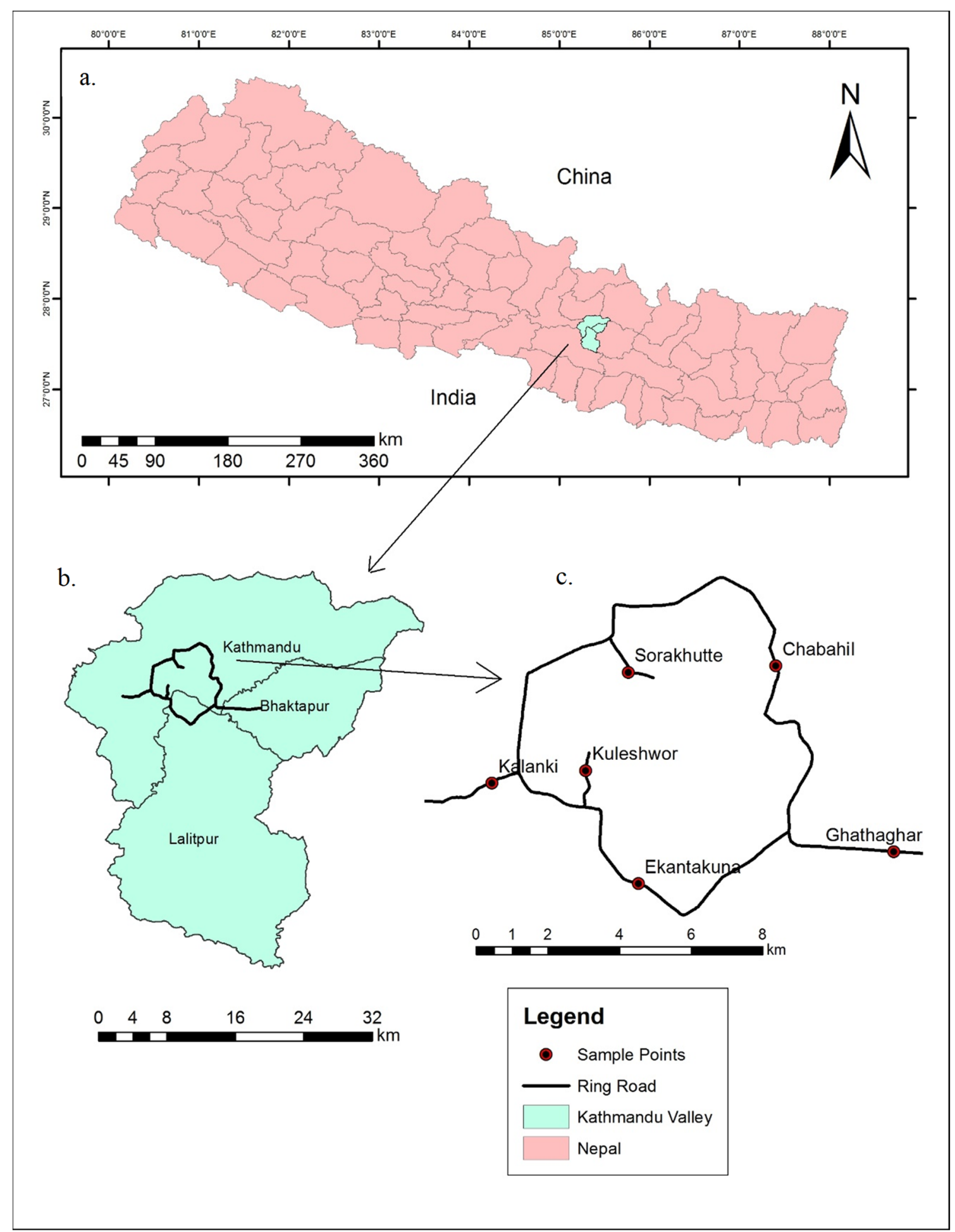

Fig. 1. (a) Map of Nepal indicating the study area (Kathmandu Valley); (b) Map of study area showing the ring road encircling Kathmandu and Lalitpur; (c) Sample points on the ring road, inside the ring road, and the arterial highways. 
dust in the vicinity so that dust plumes would not obscure the surveyors' view of exhaust plumes; and (iii) either slight uphill gradients or the presence of speed breakers.

Among the six selected locations, three had a speed breaker on the road and the other three were on gently sloping stretches. The drivers had to either accelerate after crossing the speed breaker or increase their power output to go uphill. In both cases, the surveyors were afforded the opportunity to see whether the vehicle was emitting a visible plume of smoke.

Observations were collected on one working day at each site between February and April 2017 (Table 1). The data were recorded manually during daylight hours. Only dieselpowered vehicles were counted and only the traffic flow in one direction (i.e., uphill or immediately after the speed breaker) was considered. Superemitter vehicles were differentiated from normal vehicles if the plume of black smoke was visible behind the tailpipe of those vehicles.

\section{Classification of Vehicles and Color of License Plates}

Eight vehicle types were chosen to segregate the fleet by vehicle size and transport purpose (i.e., cargo versus passenger). The cargo vehicle types were truck (carrying goods other than construction materials), tipper (carrying construction materials like sand and gravel), tanker (carrying water and oil), pickup (light-duty truck having a gross vehicle weight of $<4$ metric ton), tractor (that transports goods and also used on farms), and construction vehicle (e.g., roller and bulldozer). Because the counts were very low, construction vehicles and tractors were grouped together as a single vehicle type. Passenger vehicle types were bus ( $>26$ seats), minibus (16-25 seats), and microbus $(<15$ seats $)-$ all inclusive of the driver's seat.

In Nepal, the license-plate color distinguishes the type of owner each vehicle is registered to (Government of Nepal, 1993). In order to find some correspondence between vehicle owner and emission characteristics, the surveyed vehicles were further subdivided by the color of their license plates:

- Vehicles providing shared transport (e.g., buses and for-hire trucks) - black plate with white characters and white plate with black characters

- Privately owned vehicles - red plate with white characters

- Tourism vehicles (e.g., owned by hotels and tour operators) - green plate with white characters

- Government-owned vehicles - white plate with red characters

- Vehicles owned by national corporations (e.g., Nepal Electricity Authority, Nepal Telecom) - yellow plate with blue characters

- Diplomat-owned vehicles (e.g., United Nations fleet, Embassy employees) - blue plate with white characters

\section{Maintenance Survey}

Several surveys were conducted - between 17 April and 12 May 2017 - to characterize the patterns of diesel vehicle maintenance in the Kathmandu Valley. A total of 193 owners and drivers of different types of diesel vehicles were surveyed at Balkhu, Balaju, Kalanki, Kalimati, Ratnapark,

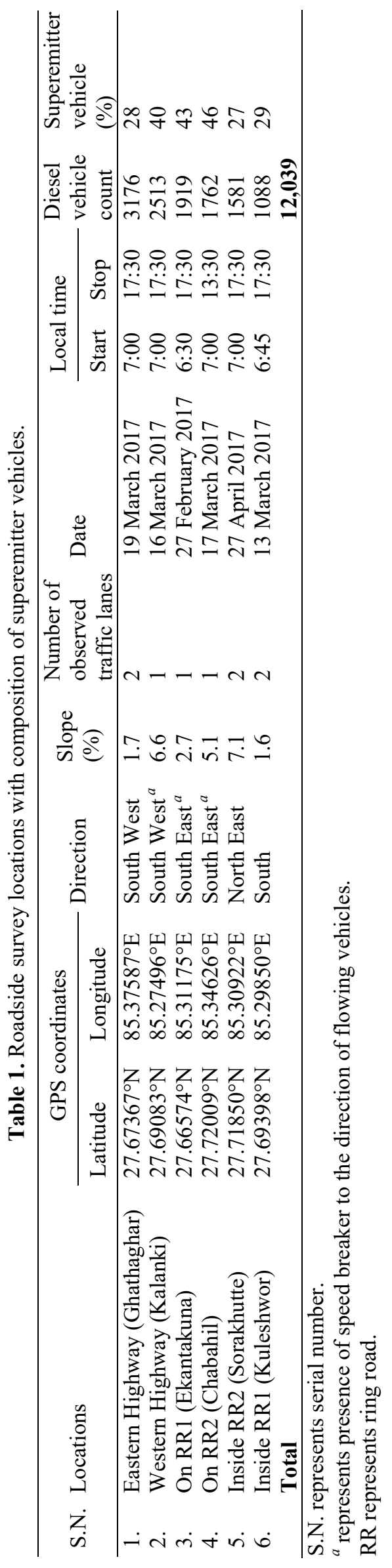


and Gongabu. In addition, 29 local maintenance centers were surveyed to get their perspectives on how closely Kathmandu drivers and vehicle owners adhered to the recommended maintenance schedules. Our initial conversations with the owners and drivers indicated a preference towards locally owned, unaffiliated workshops, and so we conducted surveys at 26 such workshops and with only 3 authorized dealers.

\section{Measurement of EF and Calculations}

The Ratnoze1 (Mountain Air Engineering, USA) portable sampling system was deployed at the maintenance centers from 28 August through 7 September 2017 to measure emissions from normal and superemitter in-use diesel vehicles under idling conditions. This system measures in situ concentrations of $\mathrm{PM}_{2.5}$ (based on the scattering coefficient), $\mathrm{CO}, \mathrm{CO}_{2}$, and $\mathrm{BC}$ (Mountain Air Engineering, 2016). The system also measures the background concentrations of gaseous pollutants like $\mathrm{CO}$ and $\mathrm{CO}_{2}$ in the dilution train. Generally, the EFs are derived from the concentration of $\mathrm{CO}$ and $\mathrm{CO}_{2}$. The error would be less when the emission concentrations of these gaseous pollutants are higher than the background concentration. To address this issue, background corrections are important and need to be included. This is the standard procedure whereby the background corrections of the samples are made; this can also be found in a previous study conducted by Stockwell et al. (2016). Pall Corporation Teflo filter membranes and quartz fiber filter membranes (of $47 \mathrm{~mm}$ diameter with $2 \mu \mathrm{m}$ pore size) were used to collect the aerosol particles within the filter holders. The mass scattering efficiency (MSE) was determined to compute the real-time concentration of $\mathrm{PM}_{2.5}$. MSE is the ratio of $\mathrm{PM}_{2.5}$ scattering coefficient to its mass concentration (Hand and Malm, 2007; Latimer and Martin, 2019). The scattering coefficient was obtained from the instrument, and the mass concentration from the filter samples by gravimetry for a given sampling period. Detailed descriptions of the equipment, flow movement and the calibration of sensors can be found in a previous study (Adhikari et al., 2019).
The exhaust was sampled for 35-80 minutes depending on vehicle availability. For some vehicles, it was feasible to collect measurements before and after servicing. The servicing of vehicles included changing engine oil, and replacing oil, diesel and air filters. The main focus with respect to superemitter vehicles was on the data obtained from roadside observations. We made 14 observations and sampled 10 vehicles (Table 2).

The average and individual fuel-based EF were calculated from the data collected during the measurement system by using the carbon mass balance method. This method is based on the fuel combustion process in which the carbon mass emitted by the vehicle exhaust equals the carbon mass of the fuel consumed (Kirchstetter et al., 1999; Moosmuller et al., 2003). In this process, $\mathrm{CO}_{2}, \mathrm{CO}$ and $\mathrm{BC}$ were considered to be the primary carbonaceous products emitted during the combustion process. The EFs were calculated using the equations reported in Adhikari et al. (2019).

\section{RESULTS AND DISCUSSIONS}

\section{Composition of Diesel Fleet by Vehicle Type}

A total of 12,039 diesel-powered vehicles were observed during our roadside survey, representing roughly a quarter of the on-road diesel vehicles registered in the Kathmandu Valley (Department of Transport Management, 2017). Our survey results (Fig. 2(a)) show that the on-road diesel fleet was relatively evenly divided between cargo carriers $(25 \%$ pickup, $16 \%$ large truck, $9 \%$ tipper, $2 \%$ tanker, and $1 \%$ tractor and construction vehicle) and passenger buses (26\% fullsized bus, $12 \%$ minibus, and 9\% microbus). This observed vehicle mix was quite consistent with the vehicle registration data from the DoTM (Table S1). A slightly higher frequency of passenger vehicles (bus, minibus, and microbus) was noted in our survey than in the registration data, while the opposite was true in the case of cargo vehicles (e.g., pickup, tipper). A likely explanation is that the buses, on an average, travel a greater distance within

Table 2. Emission factors $\left(\mathrm{g} \mathrm{L}^{-1}\right)$ of diesel vehicles tested during idling.

\begin{tabular}{|c|c|c|c|c|c|c|c|c|}
\hline \multirow{2}{*}{ S.N. } & \multirow{2}{*}{$\begin{array}{l}\text { Vehicle } \\
\text { ID }\end{array}$} & \multirow{2}{*}{$\begin{array}{l}\text { Servicing } \\
\text { status }\end{array}$} & \multirow{2}{*}{$\begin{array}{l}\text { Vehicle } \\
\text { types }\end{array}$} & \multirow{2}{*}{$\begin{array}{l}\text { Model year } \\
\text { (age of engine) }\end{array}$} & \multicolumn{4}{|c|}{ Emission factor $\left(\mathrm{g} \mathrm{L}^{-1}\right)$} \\
\hline & & & & & $\mathrm{PM}_{2.5}$ & $\mathrm{BC}$ & $\mathrm{CO}$ & $\mathrm{CO}_{2}$ \\
\hline 1. & V1 & $\mathrm{B}$ & Truck & 2002 & 30.80 & 1.067 & 46.2 & 2580 \\
\hline 2. & $\mathrm{~V} 2$ & $\mathrm{~A}$ & Truck & 2008 & $05.82^{a}$ & $0.396^{a}$ & $22.1^{a}$ & $2619^{a}$ \\
\hline 3. & V3 & $\mathrm{B}$ & Bus & 1998 & 15.50 & 1.358 & 81.3 & 2524 \\
\hline 4. & V3 & $\mathrm{A}$ & Bus & 1998 & 06.64 & 0.899 & 81.4 & 2525 \\
\hline 5. & V4 & B & Bus & 2012 & 07.29 & 0.460 & 20.4 & 2621 \\
\hline 6. & V5 & $\mathrm{B}$ & Bus & 2013 & 10.10 & 0.949 & 28.6 & 2608 \\
\hline 7. & V6 & $\mathrm{B}$ & Bus & 2016 & 07.88 & 0.253 & 46.4 & 2581 \\
\hline 8. & V7 & $\mathrm{B}$ & Bus & 2016 & 08.56 & 0.248 & 40.8 & 2590 \\
\hline 9. & V7 & A & Bus & 2016 & 03.03 & 0.211 & 48.6 & 2577 \\
\hline 10. & V8 & B & Tipper & 2016 & 04.97 & 0.285 & 37.8 & 2594 \\
\hline 11. & V8 & $\mathrm{A}$ & Tipper & 2016 & 02.67 & 0.282 & 31.9 & 2604 \\
\hline 12. & V9 & B & Tipper & 2009 & 06.52 & 0.404 & 17.3 & 2626 \\
\hline 13. & V10 & B & Pickup & 1999 & 14.60 & 1.494 & 20.3 & 2620 \\
\hline 14. & V10 & A & Pickup & 1999 & 02.71 & 0.993 & 22.2 & 2618 \\
\hline
\end{tabular}

Note: B, EF before vehicle servicing; A, EF after vehicle servicing (changing engine oil, and oil, diesel and air filters).

${ }^{a}$ represents only changing diesel filter; unable to obtain data before servicing. 
Kathmandu than do cargo vehicles (Bajracharya and Bhattarai, 2016). Supporting this explanation at the other extreme were tractors and construction vehicles (e.g., excavators, cranes, and road-construction equipment) which are known to contribute very little to the fleet total of Vehicle Kilometres Travelled (VKT). These vehicles comprised only $1 \%$ of the diesel traffic at our survey sites, but constituted $6 \%$ of the registered vehicles (Table S1).

Considerable spatial heterogeneity in the mix of diesel vehicles can be seen in Fig. 2(b). At both the survey sites inside the RR (Sorakhutte and Kuleshwor), pickup trucks made up $38 \%$ and $42 \%$, respectively, of the diesel traffic. This was noticeably higher than at the other four locations (17-25\% pickups) where heavy-duty trucks and tippers were allowed to transport goods. The highest fraction of trucks was found along the Western Highway (30\%) which is the primary route for cargo transport to/from India and southern Nepal. Trucks of this type were also quite common on the Eastern Highway (18\%) and along the RR in Ekantakuna (21\%). The highest frequency of tippers was

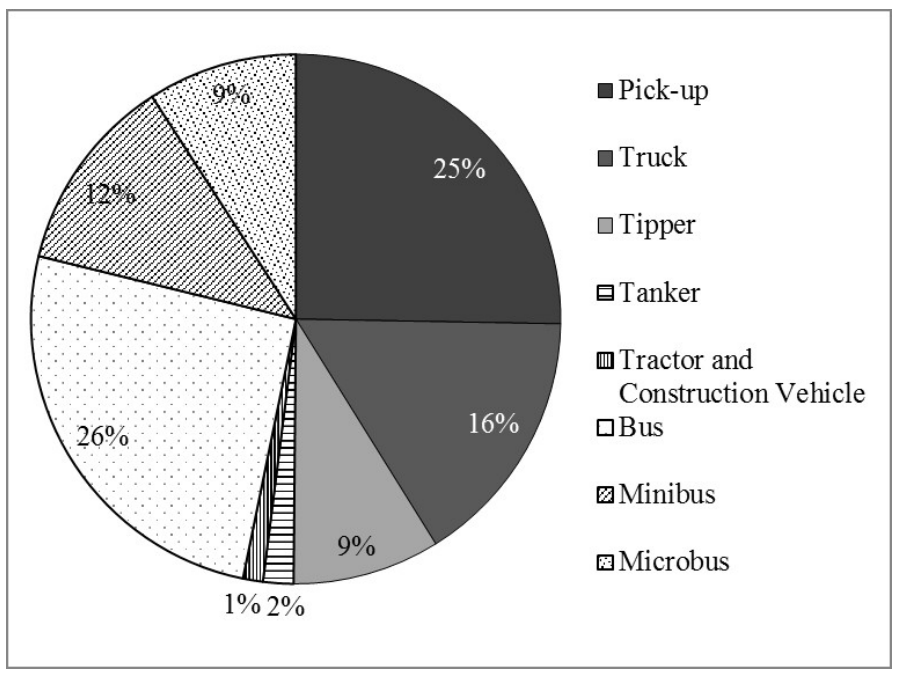

Fig. 2(a). Composition of all vehicles from roadside observations. The first five vehicle types represent cargo diesel vehicles; the remaining three types represent passenger diesel vehicles.

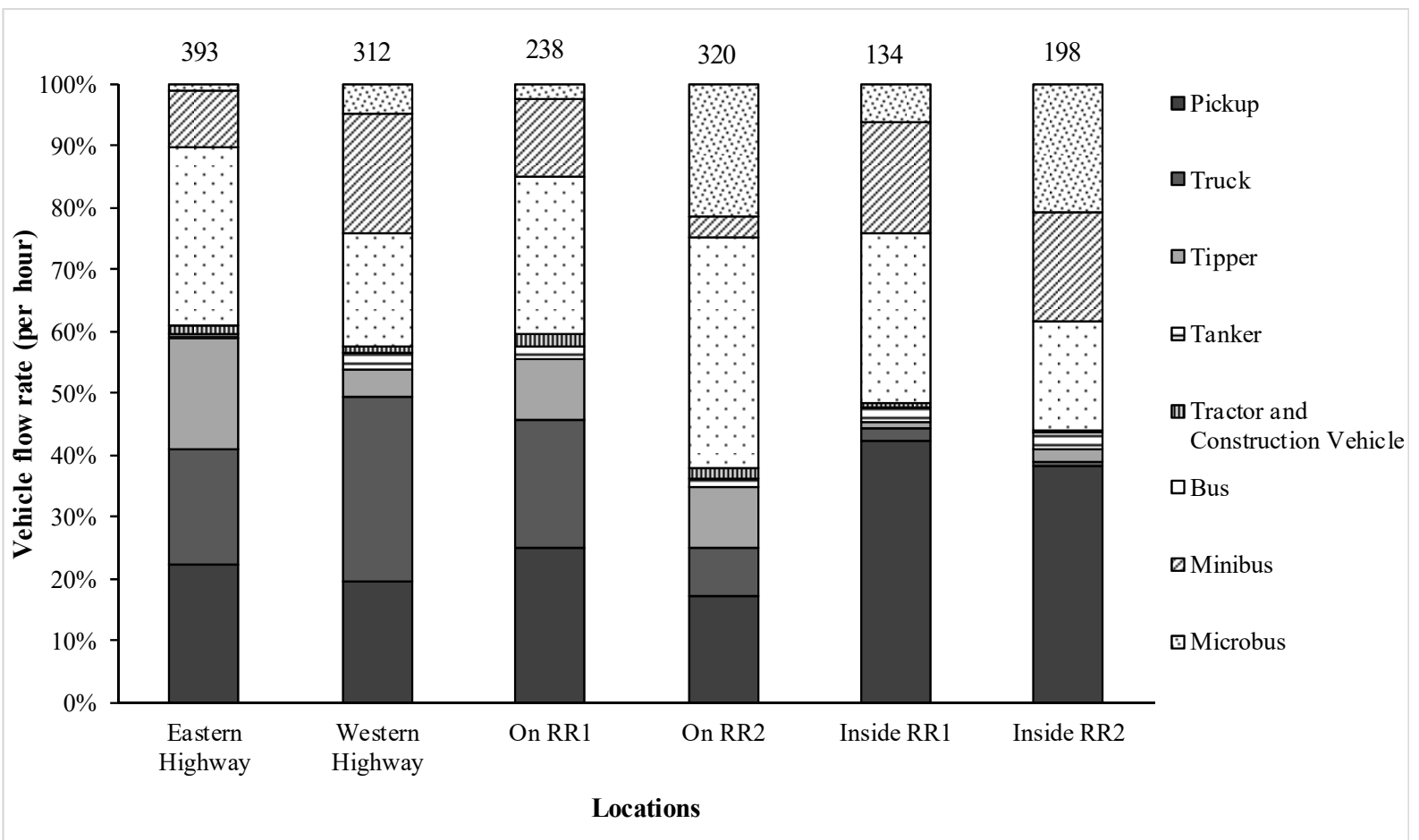

Fig. 2(b). Vehicle flow rate $\left(\mathrm{h}^{-1}\right)$ at each survey location listed above each bar for all diesel vehicles. Each data set is further subdivided into eight vehicle types (indicated by shading). The numbers above each bar represent the total number of vehicles observed at the particular location. 
found on the Eastern Highway (18\%) where the transport of construction materials is prevalent and a high concentration of brick kilns is located.

The highest fractions of buses and microbuses $(37 \%$ and $21 \%$, respectively) were along the RR in Chabahil owing to the close proximity of a bus depot. Passenger buses, as a whole, were also more than the number of cargo vehicles at both sites inside the RR, but not at the other three survey sites. Among the types of passenger buses classified in our survey, full-sized buses were the most common at all sites except on the Western Highway (where minibus presence was slightly greater at 19\%) and inside the RR at Sorakhutte where microbuses were the most common (21\%) owing to the vast network of narrow roads in proximity to that site.

The diesel vehicle flow rate was the highest on the Eastern Highway $\left(393 \mathrm{~h}^{-1}\right)$, along the eastern segment of the RR in Chabahil $\left(320 \mathrm{~h}^{-1}\right)$, and on the Western Highway $\left(312 \mathrm{~h}^{-1}\right)$. The flow rate was moderate along the south-western segment of the RR in Ekantakuna $\left(238 \mathrm{~h}^{-1}\right)$. The flow rate was the lowest inside the RR $\left(198 \mathrm{~h}^{-1}\right.$ in Sorakhutte and 134 $\mathrm{h}^{-1}$ in Kuleshwor), reflecting restrictions on heavy-duty truck traffic in the city center. One limitation of our study was that all the surveying was conducted during daylight hours so that the vehicles emitting visible plumes of soot could be distinguished accurately. Nevertheless, some informative temporal patterns in the diesel traffic were noticeable in our data set. At all the six sites, the flow rate of cargo vehicles peaked in the middle of the day (between 10:00 and 13:00) and was almost twice as high than in the morning hours (ca 07:00). However, bus traffic exhibited a completely opposite temporal profile, with flow rates at all sites reaching their minima during midday (between 11:00 and 13:30) (Figs. S2(a) and S2(b)). Peak flow rates were observed during either morning or evening commute hours - depending on the direction surveyed relative to the dominant flow of traffic - and were 2.2 times higher than the midday minimum.

\section{Composition of Diesel Fleet by Vehicle Owner}

Shared-transport vehicles constituted almost $65 \%$ of Kathmandu's diesel fleet $(7,786$ of 12,039$)$ at our survey locations (Fig. 3(b)). As one might expect, most of these were buses of varying sizes. However, a large number of them were trucks $(1,744)$ and tippers $(946)$. Most of these vehicles were hired or leased for fares. Privately owned vehicles accounted for $31 \%$ of the diesel fleet and were predominantly pickups. The remaining license-plate colors were relatively uncommon in our survey: $1.6 \%$ government owned, $1.4 \%$ tourism related, $1.2 \%$ national corporation owned, and $0.12 \%$ diplomat owned (Table S2).

An attempt was made to corroborate the ownership information gathered from our roadside survey against the government data on vehicle registrations. However, we were unable to isolate the latter by fuel type (i.e., in terms of diesel-powered vehicles). For example, 3,750 blue-plate vehicles (i.e., owned by diplomats) were registered with the government; but most of them were fueled by petrol and that fraction had not been tabulated in Nepal's registration database.
Given the sizeable body of evidence summarized above, we concluded that the 12,039 diesel vehicles observed in our survey were characteristic of Kathmandu's vehicle fleet during February-April 2017. Therefore, it is appropriate to use this database to draw conclusions about the superemitting subpopulation of vehicles within Kathmandu's diesel fleet.

\section{Prevalence of Superemitters in Kathmandu}

Altogether, 4,248 diesel vehicles (i.e., 35\% of the Kathmandu fleet) were visually identified as superemitters based on the plume of black smoke seen spewing from their tailpipes. Although this is a qualitative measure of the emissions, it lays a foundation for more quantitative studies in the future. Previous reports estimated that $20 \%$ of the diesel trucks and buses in Kathmandu were "smoke belchers" (Larssen et al., 1997), but we could not find any systematic surveys for comparison with the present results.

An analysis of Kathmandu's vehicle inspection data (Ale and Nagarkoti, 2003) found that between $25 \%$ and $40 \%$ of the diesel fleet was responsible for half of the smoke emissions from April 2000 to April 2003, which is consistent with our roadside survey findings. More recent data from Kathmandu's vehicle inspection program are unreliable owing to the inadequate calibration of equipment at the test facilities (Gurung, 2016).

It is noteworthy that the superemitter fraction is much higher in Kathmandu (i.e., 35\%) than in other countries. For example, an extensive review of relevant literature has it that about $20 \%$ of the diesel fleet in Asia and Latin America are superemitters (Bond et al., 2004). In China, about 20\% of the diesel fleet were responsible for half of the $\mathrm{BC}$ emissions in 2009 (Wang et al., 2011). In the USA, this figure drops to less than 5\% (Park et al., 2011).

\section{Influence of Speed Breakers}

Table 1 suggests some spatial variability in the superemitter fraction: that is, it is most prevalent on the RR (43-46\%) and less prevalent inside the RR (27-29\%). This variability cannot be explained by spatial differences in the vehicle mix because it persists even when the same comparison is made for individual vehicle types. For example, the superemitter fractions for each of the eight vehicle types at the RR sites are higher than the corresponding fractions inside the RR.

Ultimately, the site-to-site variability in the superemitter fraction may be attributed to differing roadway characteristics. The fraction was higher at all sites next to speed breakers than at any of the sites where traffic was free-flowing (Table 1). This result held true for individual vehicle types as well. There is a statistically significant difference between the proportion of emitters in speed breaker and free-flowing road conditions. The implication is that the diesel vehicles in Kathmandu are more likely to belch smoke during acceleration (i.e., immediately after passing over a speed breaker) than when driving up a slope (1.6-7.1\%) (Table 1).

\section{Superemitters by Vehicle Type}

It is evident that the vehicle types with the highest 
superemitting fractions were truck (51\%), tanker (50\%), and tractor and construction vehicle (48\%); the three vehicle types with the lowest superemitting fractions were pickup (27\%), minibus (27\%), and tipper (29\%) (Fig. 3(a)). Most of the trucks and tankers were old (Department of Transport Management, 2017) and did not comply with European Union norms. This has led to higher emissions from these types of old vehicles. However, tippers being the newly introduced heavy vehicles to the Kathmandu Valley fleet (Department of Transport Management, 2017) are compliant with Euro III norms, and have more advanced engine modifications than the older vehicles. Consequently, these vehicles were found to emit less. The majority of the tractor category included in this study had a small engine capacity, but high emissions. Usually, most of these tractors were old and had two-stroke engines. These types of engines are less efficient in fuel utilization and lack efficient lubrication systems, thereby exacerbating engine wear and tear, and increasing the emissions (Manufacturers of Emission Controls Association, 2014; Alves et al., 2015).

When focusing on data from the sites with speed breakers, a significant difference was found between the microbuses at Chabahil (on RR2) and those at Kalanki (on the Western Highway). There was a higher number of superemitter microbuses at Chabahil. This might have been because, among the shared microbuses that are only used on the RRs, the majority were superemitters. The other influencing factors for this might also be traffic congestion and road conditions, which triggered a higher number of full-size superemitter buses at Chabahil compared to Kalanki.

At sites with free-flowing traffic, the most significant difference in emission characteristics was found between the full-size buses at Kuleshwor (in RR1) and those at Ghathaghar (on the Eastern Highway). Most of the full-size Nepal Yatayat buses at Kuleshwor were superemitters; but these were found to be absent at Ghathaghar. This might have resulted in a higher number of superemitter vehicles in
Kuleshwor.

\section{Superemitters by Vehicle Owner}

The highest superemitter vehicles were shared-transport ones (39\%) (Fig. 3(b)). This result was similar to those reported in the study by Ale and Nagarkoti (2003) in 20002001 and 2001-2002. One explanation may be that sharedtransport vehicles are most extensively utilized, often to the point of overloading (Faiz et al., 2006). In addition, people pay less to use these facilities, and so the owners are less concerned about maintaining their vehicles. The superemitting fraction was the lowest for tourism vehicles $(16 \%)$ and diplomatic vehicles $(0 \%)$. Tourism is one of the income-based sectors that provides and attracts its guests with the best facilities, and so tourist vehicles are clean and well maintained. The diplomatic vehicles are the highest standard vehicle type in Kathmandu's fleet and are maintained regularly. These two sectors do not favor old, inferior vehicles and prefer those with lower emissions.

For a few vehicle types, our data set is large enough to explore whether the emission characteristics are significantly affected by vehicle ownership. For example, we found that almost all national corporation tankers were superemitters (15 of 16), whereas the opposite was true of private tankers (5 of 31). Among the more common vehicle types, we should note that microbuses with black plates were twice as likely to be identified as superemitters (40\%) than microbuses that were not shared-transport $(20 \%)$.

\section{Vehicle Servicing}

Vehicle servicing was based both on travel distance and working period. Vehicle servicing (except for tractor and construction vehicle) was based on the distance travelled. The total cost of general servicing for each vehicle type included the cost of engine oil; oil, diesel and air filters; and labor. The average total cost of general servicing ranged between USD 16 for tractor and USD 203 for construction

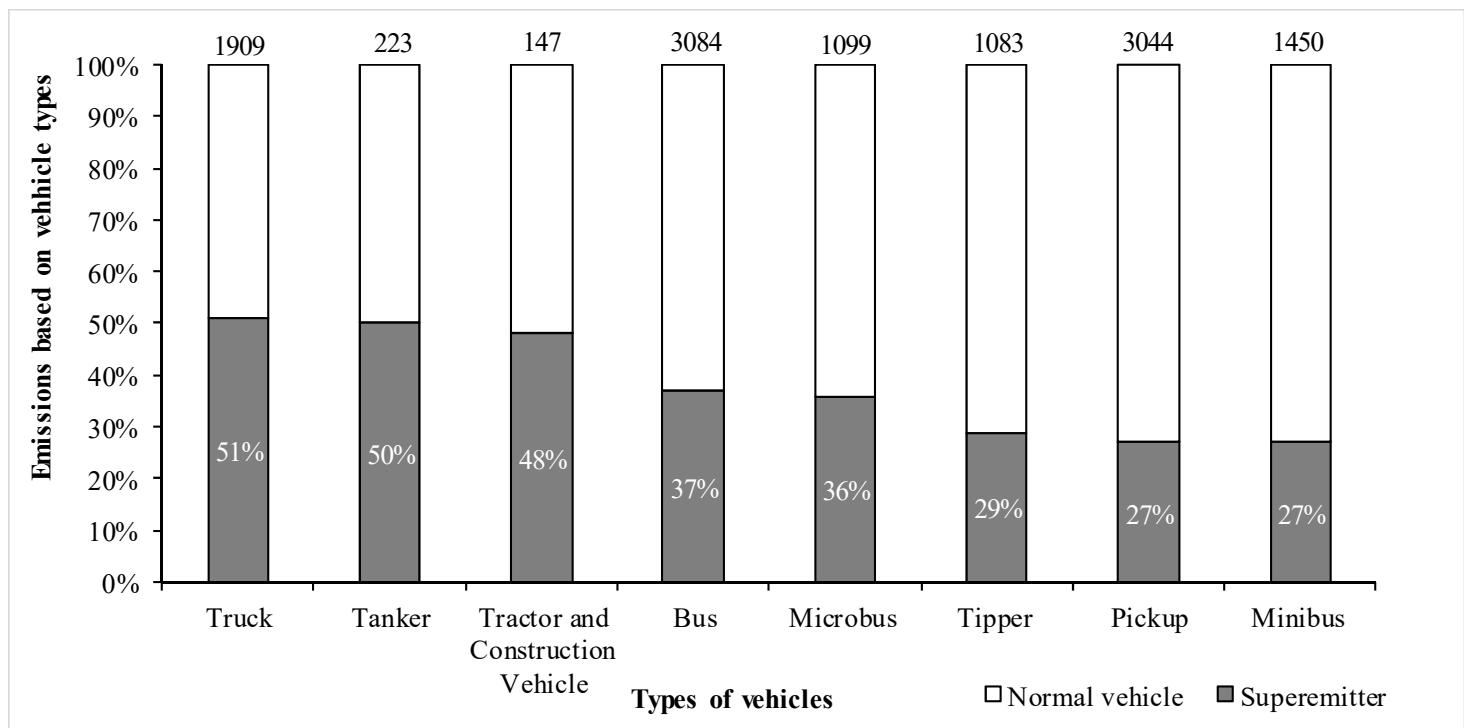

Fig. 3(a). Composition of superemitter vehicles based on vehicle types. The numbers above each bar represent the total number of individual vehicle types that were observed. 


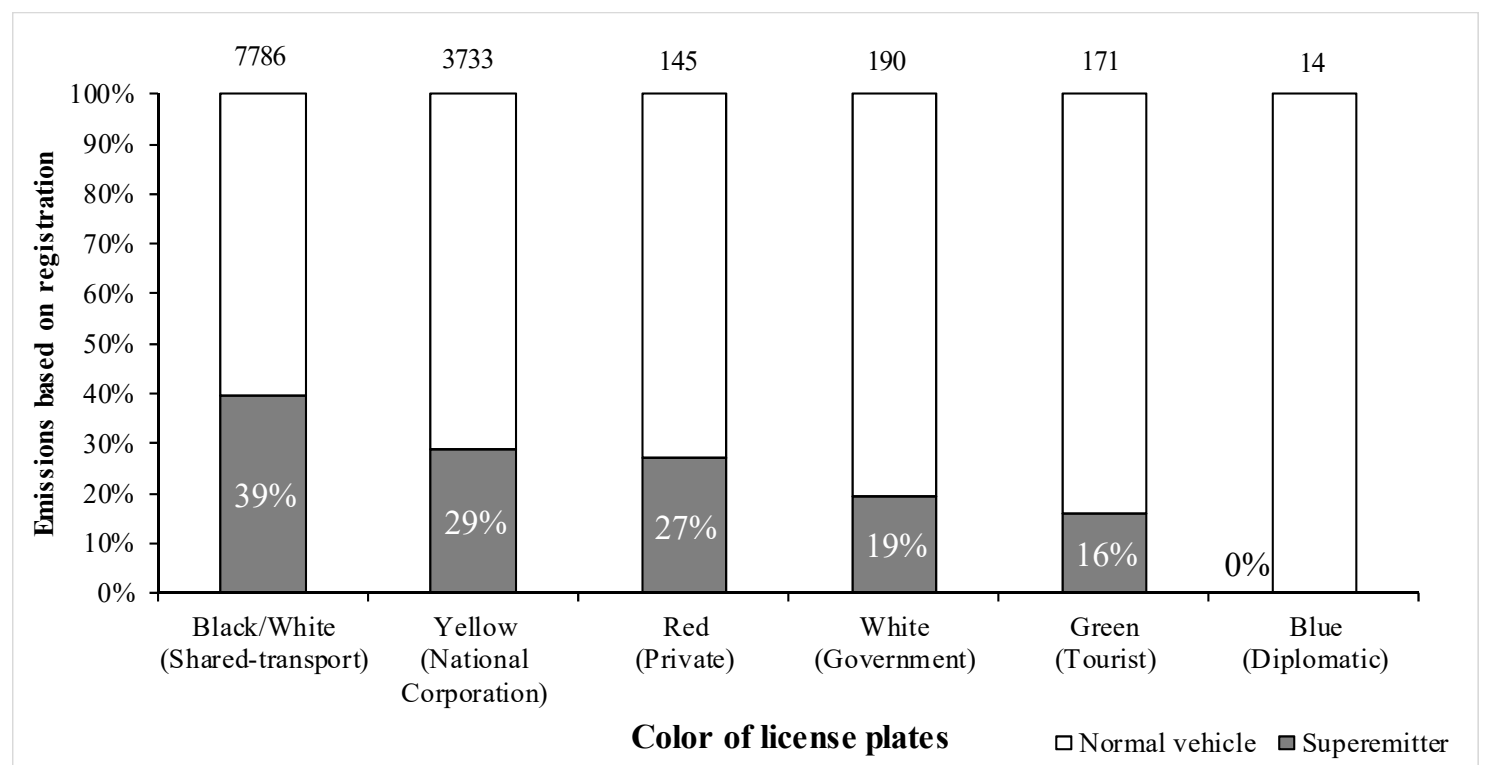

Fig. 3(b). Composition of superemitter vehicles based on registration. "Shared-transport" represents both the vehicles having black plates and white figures, and those with white plates and black figures. The numbers above each bar represent the total number of observed vehicles with particular color of license plates.

vehicle depending on the size of vehicle included in this study (Table S3). The cost of servicing varied according to the engine size of the vehicle. For example, the maximum total cost was for a construction vehicle with the highest engine capacity, and the minimum was for a tractor with the lowest engine capacity. The total costs of servicing were similar for all types of vehicle, according to the respondents from vehicle owners and local maintenance centers, with the difference ranging between $1 \%$ and $25 \%$. In addition, most (71\%) respondents were found to perform routine servicing of vehicles, of which $70 \%$ were normal (non-emitters). However, among $29 \%$ of the non-routinely serviced vehicles, $53 \%$ were superemitters.

\section{EF of Diesel Vehicles}

Fuel-based EFs were used in this study because their variation is comparatively less in terms of driving mode, vehicle weight and engine power compared to travel-based EFs (Kean et al., 2003; Park et al., 2011; Fu et al., 2012). The fuel-based EFs of pollutants that were measured during idling are shown in Table 2. The EFs of CO, $\mathrm{PM}_{2.5}$ and $\mathrm{BC}$ ranged between $17.3 \mathrm{~g} \mathrm{~L}^{-1}$ and $81.3 \mathrm{~g} \mathrm{~L}^{-1}, 4.97 \mathrm{~g} \mathrm{~L}^{-1}$ and $30.80 \mathrm{~g} \mathrm{~L}^{-1}$, and $0.248 \mathrm{~g} \mathrm{~L}^{-1}$ and $1.494 \mathrm{~g} \mathrm{~L}^{-1}$, respectively, before servicing (Table 2). It is notable that during idling of heavy diesel vehicles, the EFs of $\mathrm{PM}_{2.5}$ and $\mathrm{BC}$ were higher than in other countries (Table 3). For example, the average EFs of $\mathrm{PM}_{2.5}$ and $\mathrm{BC}$ for heavy diesel vehicles in this study were $18.62 \mathrm{~g} \mathrm{~kg}^{-1}$ and $0.827 \mathrm{~g} \mathrm{~kg}^{-1}$, respectively. In a 2007 study performed by Park et al. (2011) in the USA, they were reported to be $0.37 \mathrm{~g} \mathrm{~kg}^{-1}$ and $0.220 \mathrm{~g} \mathrm{~kg}^{-1}$, respectively, during idling. Another example comes from China where the EF of BC was $0.160 \mathrm{~g} \mathrm{~kg}^{-1}$ for heavy diesel vehicles (Deng et al., 2017). This clearly represents high variations in EFs of $\mathrm{PM}_{2.5}$ and $\mathrm{BC}$. However, the average EF of $\mathrm{CO}$ was found to be low compared to the study conducted by
Park et al. (2011).

The emissions from diesel vehicles during idling are different from those when driving which are measured to obtain realistic data from diesel vehicles. There are various approaches to measure the EFs from these vehicles, like dynamometer and tunnel tests, which represent the different modes of driving conditions. However, dynamometer tests are quite expensive, while tunnel tests are limited to specific driving conditions. The present study was conducted for the first time in Nepal and in Kathmandu Valley to measure the EFs from diesel vehicles. We were able to measure the EFs in the idling condition as it was comparatively cheap, and this helped us obtain realistic EFs from the diesel vehicles at the local level. Although the EFs in the idling condition vary from those in the driving condition, still the data represents certain percentage of the latter. An earlier study observed that EFs of pollutants during the idling condition represents about 5 to $75 \%$ of the driving condition (McCormick et al., 2000). Another study reported the representation of pollutants during the idling condition to be in the range of 66 to $74 \%$ of the driving condition (Park et al., 2011). Although we were not able to perform the study during the driving condition, we can still compare the EFs obtained in the idling condition to those in the driving condition through these representative values. In this study, we compared idling EF with driving EF through the representative data given by Park et al. (2011). The EF of $\mathrm{PM}_{2.5}$ in the idling condition calculated in this study was high compared to what the studies found in the USA, China, Germany and Switzerland during the driving condition, for both light and heavy diesel vehicles (Weingartner et al., 1997; Kirchstetter et al., 1999; Ban-Weiss et al., 2008; Schneider et al., 2008; Liu et al., 2009; Wang et al., 2011; Huo et al., 2012) (Table 3). The EF of BC was also found to be higher compared to what the studies found in the USA, 


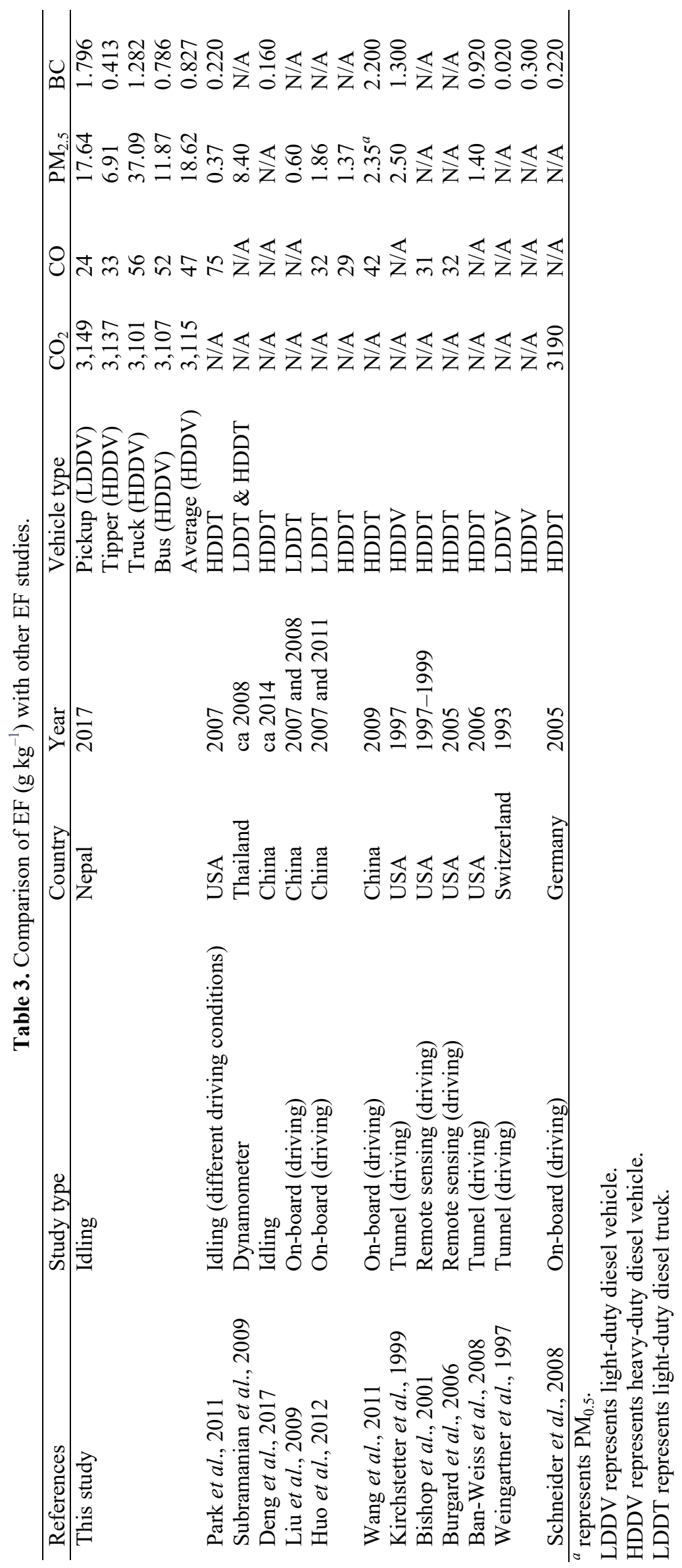


Germany and Switzerland during the driving condition, for both the light and heavy diesel vehicles (Weingartner et al., 1997; Ban-Weiss et al., 2008; Schneider et al., 2008). However, the $\mathrm{EF}$ of $\mathrm{BC}$ observed in this study was also found to be lower compared to what the studies found in the USA in 1997 and China in 2009 for heavy diesel vehicles (Kirchstetter et al., 1999; Wang et al., 2011). The EF of CO for light- and heavy-duty vehicles was similar to what the studies found in the USA and China (Burgard et al., 2006; Bishop et al., 2001; Wang et al., 2011; Huo et al., 2012) (Table 3). These comparisons helped us to get a general idea about the EFs of diesel vehicles in the Kathmandu Valley with respect to those of other places in the world.

Of the three different pollutants, the variations in the EF of $\mathrm{PM}_{2.5}$ were the most prominent. There are various reasons behind this apparent inconsistency in the emission data proffered by earlier studies conducted in different countries. They may include fuel composition; design and age of engine; manufacturing company; operating conditions; maintenance pattern; road conditions; traffic conditions; and environmental conditions (such as temperature, pressure, humidity, and altitude) during the measurements.

\section{Influence of Vehicle Age on EF}

The EFs of $\mathrm{CO}, \mathrm{PM}_{2.5}$ and $\mathrm{BC}$ were at their maximum for bus, truck, and pickup, respectively, during idling (Table 2). These three types of vehicle tested were older (more than 15 years) than the other vehicles tested in this study. The new vehicles (such as tippers and buses) had comparatively lower emissions than old trucks and buses. The EFs of $\mathrm{PM}_{2.5}, \mathrm{BC}$ and $\mathrm{CO}$ for old trucks were more than fivefold, more than threefold, and one-threefold higher, respectively, than for new tippers. Similarly, the EFs of $\mathrm{PM}_{2.5}, \mathrm{BC}$ and CO for old buses were twofold, one-fivefold, and two-fourfold higher, respectively, than for new buses. The study of heavy diesel vehicles conducted by Chen et al. (2007) indicated that in China, the EF of CO for old vehicles was threefold higher than for new vehicles. Another study conducted in Slovenia in 2011 disclosed the EF of BC for old, heavy diesel vehicles (of more than 10 years) to be $41 \%$ more than those for new vehicles (of 5-10 years) (Jezek et al., 2015). Similarly, in China, PM emissions were higher in the case of old vehicles (China III emission standard) compared to the new ones (China IV emission standard) in 2016 (Wang et al., 2018). The possible reason behind the high EF from old vehicles might have to do with poor engine combustion and irregular maintenance (Faiz et al., 2006; Chen et al., 2007).

\section{Impact of Servicing on $\boldsymbol{E F}$}

The average EFs of $\mathrm{PM}_{2.5}$ and $\mathrm{BC}$ reduced by $66 \%$ and $30 \%$, respectively, just after vehicle servicing; however, the $\mathrm{EF}$ of $\mathrm{CO}$ increased by $2 \%$ during idling when averaged across four vehicles (Fig. 4). The EFs for both the conditions, before and after servicing, were higher in the beginning, and later on, decreased and attained a stage of stability (Figs. 5(a), 5(b) and 5(c)). The EF of $\mathrm{PM}_{2.5}$ reduced by $57 \%$ and $\mathrm{BC}$ by $34 \%$ after servicing, particularly in the case of old buses. Similarly, the EFs of $\mathrm{PM}_{2.5}$ and BC reduced by $65 \%$ and $15 \%$, respectively, after new buses were serviced. One limitation in measurement was that there were no old, heavy cargo diesel vehicles for us to observe the impact of servicing. However, in the case of new tippers, we observed reductions in the EFs of $\mathrm{PM}_{2.5}$ and $\mathrm{BC}$ by $46 \%$ and $1 \%$, respectively, after servicing. In addition, servicing an old, light-duty vehicle (e.g., pickup) resulted in reductions in the EFs of $\mathrm{PM}_{2.5}$ and $\mathrm{BC}$ by $81 \%$ and $34 \%$, respectively. Surprisingly, there was an increase in the EF of $\mathrm{CO}$ in both heavy- and light-duty vehicles of any age (old and new) after servicing. A similar case was observed in a previous study conducted for gasoline vehicles (Stockwell et al., 2016). The exact reason for this is still unknown (Stockwell et al., 2016). Further detailed studies with a greater sample size are needed to understand this unusual increase in the EF of $\mathrm{CO}$ after servicing. However, the EF of CO decreased by $16 \%$ in the case of new tipper. Overall, it can be said that vehicle servicing helps to reduce emissions from different types of vehicles of any age, thereby contributing to the mitigation of diesel emissions in the Kathmandu Valley.

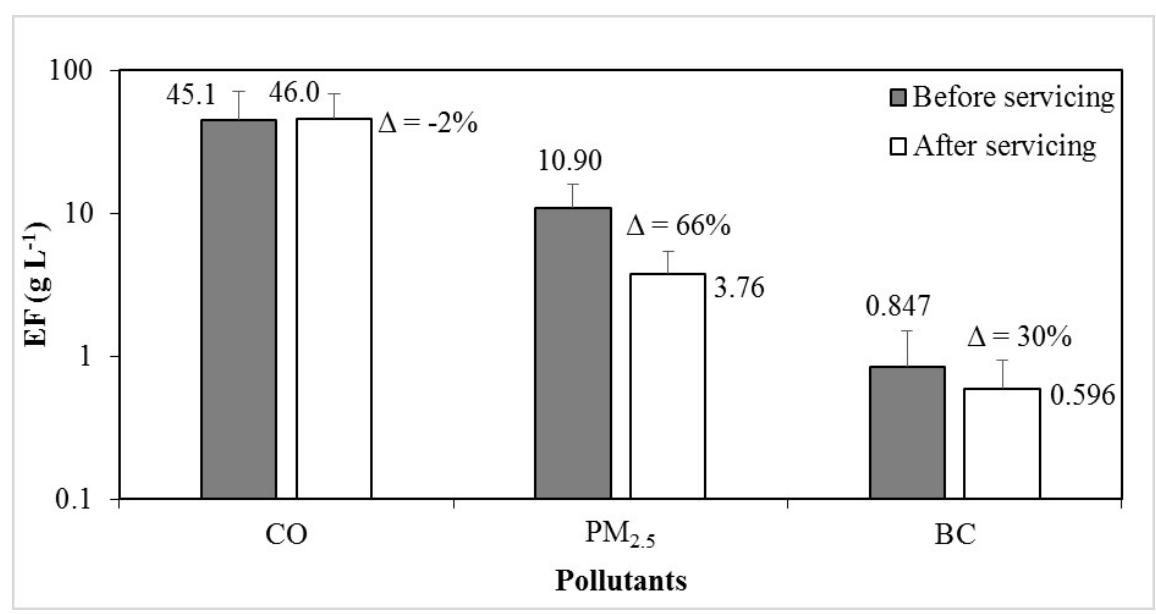

Fig. 4. Impact of servicing on EFs of $\mathrm{CO}, \mathrm{PM}_{2.5}$, and $\mathrm{BC}$. Servicing included changing the engine oil, and replacing oil, diesel and air filters. 


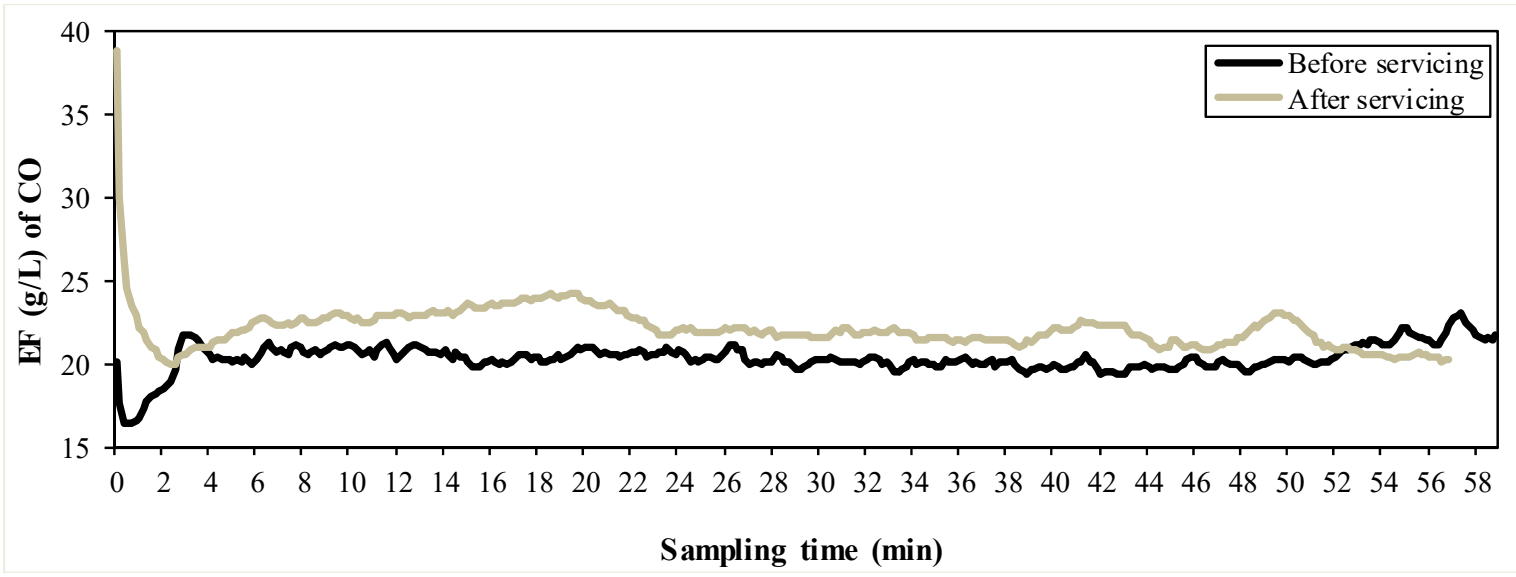

Fig. 5(a). Real-time EFs of $\mathrm{CO}$ for pick-up before and after servicing.

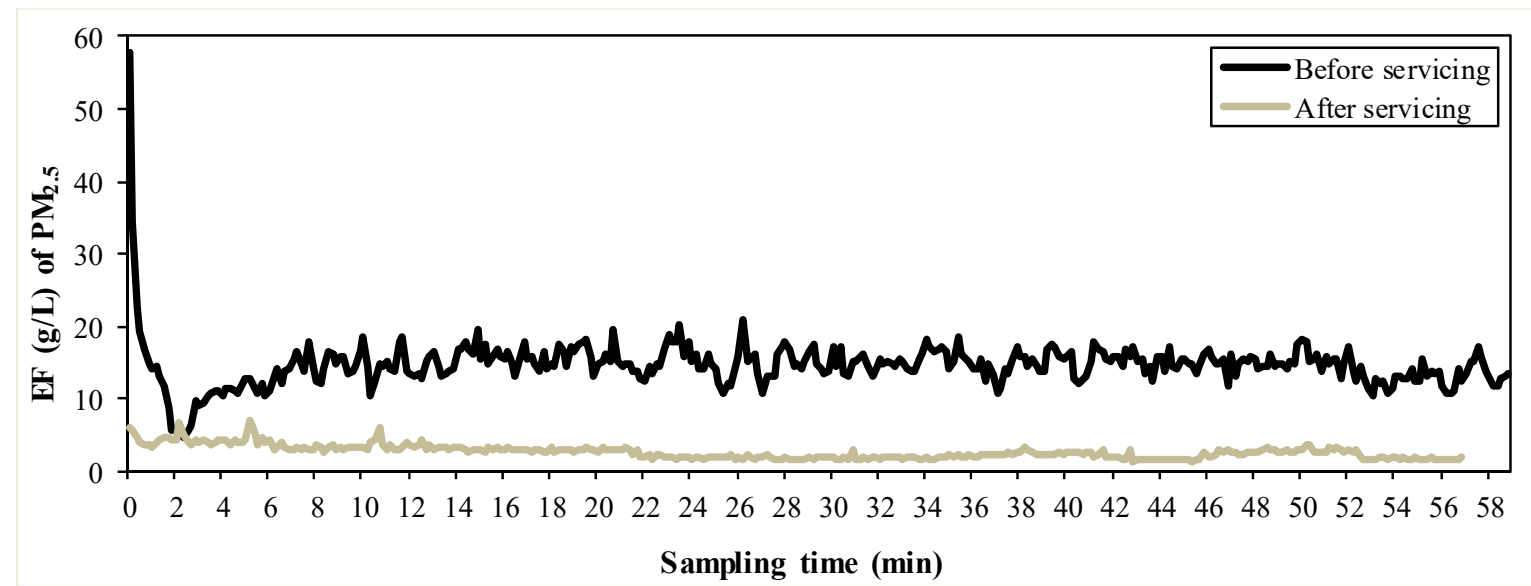

Fig. 5(b). Real-time EFs of $\mathrm{PM}_{2.5}$ for pick-up before and after servicing.

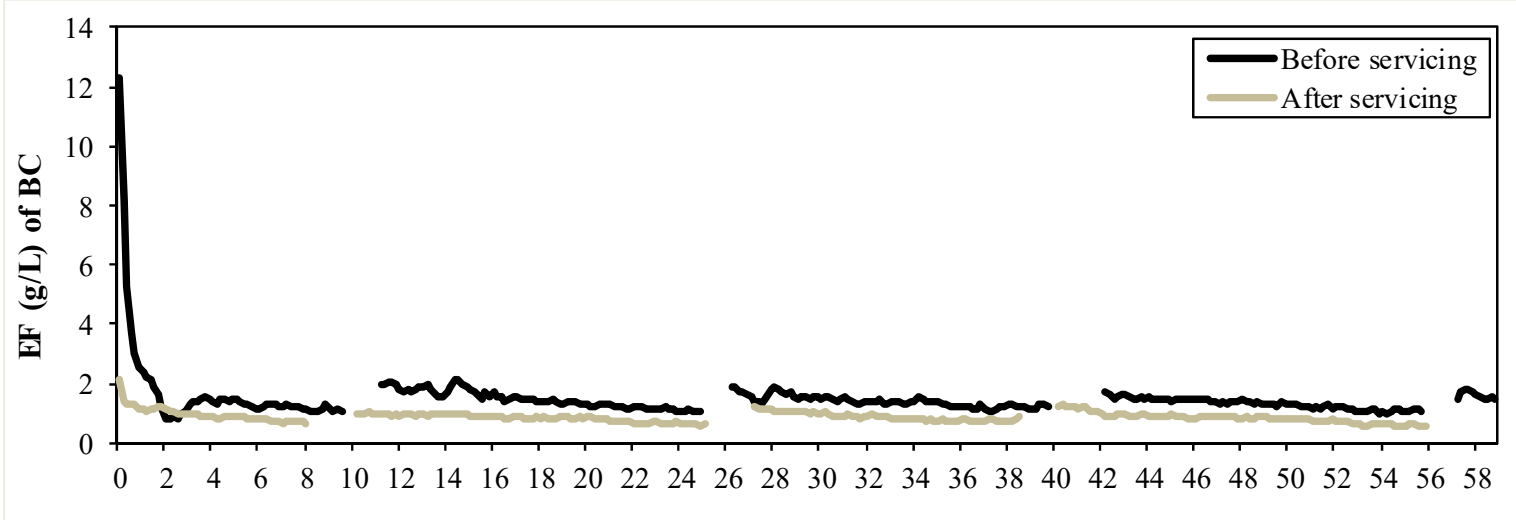

Sampling time (min)

Fig. 5(c). Real-time EFs of BC for pick-up before and after servicing.

\section{CONCLUSIONS}

This is the first study of its kind in Nepal which provides the EFs of $\mathrm{PM}_{2.5}, \mathrm{BC}$ and $\mathrm{CO}$ from diesel vehicles, while also exploring the impact of servicing on emissions. It presents roadside observations of diesel vehicles in the Kathmandu Valley, discusses the cost of general servicing, and provides measurements of the EF during idling condition from diesel vehicles. From these roadside observations, we found that only some specific vehicles in the entire diesel vehicle fleet were superemitters. We compared the EF during idling from this study with previous studies and found them to be higher than in other countries. The average total cost of general servicing for all types of vehicle was 
approximately USD 90-100. General vehicle servicing reduces the $\mathrm{EF}$ of $\mathrm{PM}_{2.5}$ by $66 \%$ and of $\mathrm{BC}$ by $30 \%$ during idling. However, the study does not report an improvement in the EF of CO after servicing. The EFs presented here do not in themselves represent the entire diesel vehicle fleet of the Kathmandu Valley. However, the data provides a strong foundation for future research in the field of diesel vehicle emissions. Thus, this study helps in providing initial inputs toward the preparation of an emission inventory for diesel vehicles which can be used in quantifying global emissions, and it also provides a base to explore the cost-effectiveness of mandating routine servicing in order to mitigate vehicular pollution in the Kathmandu Valley.

There exists some limitations which we were not able to address in the present study. The roadside observations were not conducted during night-time due to safety issues. Similarly, the emissions from vehicles were not characterized based on speed of vehicles, seasonality of driving pattern as well as observations were not conducted during weekends. The EFs were also not measured during driving on plain or slope, and loading or unloading; further we were not able to carry out follow-up measurements after servicing due to strong resistance from the vehicle owners. Moreover, it was highly difficult to track down the same vehicle and get the owner's consent for undertaking emission measurements. In order to overcome such limitations, it is highly essential that academic, governmental and non-governmental agencies are brought together to organize larger campaigns in order to generate robust data on EFs from diesel vehicles.

\section{ACKNOWLEDGEMENTS}

This study was partially supported by core funds of ICIMOD contributed by the governments of Afghanistan, Australia, Austria, Bangladesh, Bhutan, China, India, Myanmar, Nepal, Norway, Pakistan, Sweden, and Switzerland. The views and interpretations in this publication are those of the authors and are not necessarily attributable to ICIMOD. The study team would like to acknowledge the fieldwork assistance offered by Ms Pratiksha Pant, Ms Sandila Shrestha, Ms Jyoti Lamichhane and Mr Aayush Maharjan. We also thank the local shopkeepers for providing the hospitality that facilitated our roadside surveys; and respondents at local and authorized maintenance centers for giving us information, as well as the space to set up our instruments alongside the vehicles to carry out measurements of emissions. We would like to acknowledge Dr. Parth Sarathi Mahapatra for fruitful discussions. Acknowledgements are also due to Elaine Monaghan for English editing of the manuscript. The authors would also like to thank both the anonymous reviewers for helping us improve the quality of the manuscript and editor for smooth handling of the manuscript. Finally, we would like to express our gratitude to all those helping hands whose contribution made this research study possible.

\section{SUPPLEMENTARY MATERIAL}

Supplementary data associated with this article can be found in the online version at http://www.aaqr.org.

\section{REFERENCES}

Adhikari, S., Mahapatra, P.S., Sapkota, V. and Puppala, S.P. (2019). Characterizing emissions from agricultural diesel pumps in the Terai region of Nepal. Atmosphere 10: 56.

Ale, B.B. and Nagarkoti, R.K. (2003). Evaluation of Kathmandu Valley inspection and maintenance program on diesel vehicles. J. Inst. Eng. 3: 81-87.

Alves, C.A., Lopes, D.J., Calvo, A.I., Evtyugina, M., Rocha, S. and Nunes, T. (2015). Emissions from lightduty diesel and gasoline in-use vehicles measured on chassis dynamometer test cycles. Aerosol Air Qual. Res. 15: 99-116.

Bajracharya, I. and Bhattarai, N. (2016). Road transportation energy demand and environmental emission: A case of Kathmandu valley. Hydro Nepal: J. Water, Energy Environ. 18: 30-40.

Ban-Weiss, G.A., McLaughlin, J.P., Harley, R.A., Lunden, M.M., Kirchstetter, T.W., Kean, A.J., Strawa, A.W., Stevenson, E.D. and Kendall, G.R. (2008). Long-term changes in emissions of nitrogen oxides and particulate matter from on-road gasoline and diesel vehicles. Atmos. Environ. 42: 220-232.

Bhandarkar, S. (2013). Vehicular pollution, their effect on human health and mitigation measures. Veh. Eng. 1: 3340.

Bishop, G.A. and Stedman, D.H. (2008). A decade of onroad emissions measurements. Environ. Sci. Technol. 42: 1651-1656.

Bishop, G.A., Morris, J.A., Stedman, D.H., Cohen, L.H., Countess, R.J., Countess, S.J., Maly, P. and Scherer, S. (2001). The effects of altitude on heavy-duty diesel truck on-road emissions. Environ. Sci. Technol. 35: 15741578.

Bond, T.C., Streets, D.G., Yarber, K.F., Nelson, S.M., Woo, J.H. and Klimont, Z. (2004). A technology-based global inventory of black and organic carbon emissions from combustion. J. Geophys. Res. 109: D14203.

Bond, T.C. and Sun, H. (2005). Can reducing black carbon emissions counteract global warming? Environ. Sci. Technol. 39: 5921-5926.

Burgard, D.A., Bishop, G.A., Stedman, D.H., Gessner, V.H. and Daeschlein, C. (2006). Remote sensing of in-use heavy-duty diesel trucks. Environ. Sci. Technol. 40: 6938-6942.

Chen, C., Huang, C., Jing, Q., Wang, H., Pan, H., Li, L., Zhao, J., Dai, Y., Huang, H., Schipper, L. and Streets, D.G. (2007). On-road emission characteristics of heavyduty diesel vehicles in Shanghai. Atmos. Environ. 41: 5334-5344.

Colbeck, I., Nasir, Z.A. and Ali, Z. (2010). The state of ambient air quality in Pakistan-A review. Environ. Sci. Pollut. Res. 17: 49-63.

Deng, W., Hu, Q., Liu, T., Wang, X., Zhang, Y., Song, W., Sun, Y., Bi, X., Yu, J., Yang, W., Huang, X., Zhang, Z., Huang, Z., He, Q., Mellouki, A. and George, C. (2017). Primary particulate emissions and secondary organic 
aerosol (SOA) formation from idling diesel vehicle exhaust in China. Sci. Total Environ. 593: 462-469.

Department of Environment (2017). Air quality management action plan for kathmandu valley, http://www.indiaenvir onmentportal.org.in/files/file/Report\%20on\%20AQM\% 20Action\%20Plan\%202017.pdf, Last Access: 7 March 2019.

Department of Transport Management (2017). Details of registration of transport up to fiscal year 2046/47-072/73, https://www.dotm.gov.np/en/vehicle-registration-record/, Last Access: 7 March 2019.

Edgerton, S.A., Bian, X., Doran, J.C., Fast, J.D., Hubbe, J.M., Malone, E.L., Shaw, W.J., Whiteman, C.D., Zhong, S., Arriaga, J.L., Ortiz, E., Ruiz, M., Sosa, G., Vega, E., Limon, T., Guzman, F., Archuleta, J., Bossert, J.E., Elliot, S.M., Lee, J.T., McNair, L.A., Chow, J.C., Watson, J.G., Coulter, R.L., Doskey, P.V., Gaffney, J.S., Marley, N.A., Neff, W. and Petty, R. (1999). Particulate air pollution in Mexico City: A collaborative research project. J. Air Waste Manage. Assoc. 49: 1221-1229.

Faiz, A., Ale, B.B. and Nagarkoti, R.K. (2006). The role of inspection and maintenance in controlling vehicular emissions in Kathmandu Valley, Nepal. Atmos. Environ. 40: 5967-5975.

Fu, M., Ge, Y., Tan, J., Zeng, T. and Liang, B. (2012). Characteristics of typical non-road machinery emissions in China by using portable emission measurement system. Sci. Total Environ. 437: 255-261.

Gautam, C. (2006). Final report on action program on air quality management of Kathmandu Valley, Ministry of Science, Environment and Technology, Government of Nepal, Kathmandu.

Ghimire, K.P. and Shrestha, S.R. (2014). Estimating vehicular emission in Kathmandu Valley, Nepal. Int. J. Environ. 3: 133-146.

Government of Nepal (1993). Motor vehicles and transport management act, 1993, http:/www.ccwb.gov.np/uploads/ Resource/Lawpolicies/Act/motor-vehicles-and-transportmanagement-act.pdf, Last Access: 7 March 2019.

Gurung, P. (2016). Challenges of curbing vehicle emissions, https://myrepublica.nagariknetwork.com/news/4064/, Last Access: 7 March 2019.

Hand, J.L. and Malm, W.C. (2007). Review of aerosol mass scattering efficiencies from ground-based measurements since 1990. J. Geophys. Res. 112: D16203.

Huo, H., Yao, Z., Zhang, Y., Shen, X., Zhang, Q. and He, K. (2012). On-board measurements of emissions from diesel trucks in five cities in China. Atmos. Environ. 54: 159-167.

Jayarathne, T., Stockwell, C.E., Bhave, P.V., Praveen, P.S., Rathnayake, C.M., Islam, M.R., Panday, A.K., Adhikari, S., Maharjan, R., Goetz, J.D., DeCarlo, P.F., Saikawa, E., Yokelson, R.J. and Stone, E.A. (2018). Nepal Ambient Monitoring and Source Testing Experiment (NAMaSTE): Emissions of particulate matter from wood- and dungfueled cooking fires, garbage and crop residue burning, brick kilns, and other sources. Atmos. Chem. Phys. 18: 2259-2286.

Jezek, I., Katrasnik, T., Westerdahl, D. and Mocnik, G.
(2015). Black carbon, particle number concentration and nitrogen oxide emission factors of random in-use vehicles measured with the on-road chasing method. Atmos. Chem. Phys. 15: 11011-11026.

Jha, P.K. (2001). Transport sector technical inspection system in Nepal. Central Department of Botany, Tribhuvan University, Kirtipur, Kathmandu, p. 13.

Kean, A.J., Harley, R.A. and Kendall, G.R. (2003). Effects of vehicle speed and engine load on motor vehicle emissions. Environ. Sci. Technol. 37: 3739-3746.

Kim, B.M., Park, J.S., Kim, S.W., Kim, H., Jeon, H., Cho, C., Kim, J.H., Hong, S., Rupakheti, M., Panday, A.K., Park, R.J., Hong, J. and Yoon, S.C. (2015). Source apportionment of $\mathrm{PM}_{10}$ mass and particulate carbon in the Kathmandu Valley, Nepal. Atmos. Environ. 123: 190199.

Kirchstetter, T.W., Harley, R.A., Kreisberg, N.M., Stolzenburg, M.R. and Hering, S.V. (1999). On-road measurement of fine particle and nitrogen oxide emissions from light- and heavy-duty motor vehicles. Atmos. Environ. 33: 2955-2968.

Larssen, S., Gram, F., Haugsbakk, I., Jansen, H., Olsthoorn, X., Giri, A.S., Shah, R., Shrestha, M.L., Shrestha, B., Shah, J.J. and Nagpal, T. (1997). Urban Air Quality Management Strategy in Asia: Kathmandu Valley, The World Bank, Washington D. C., p. 174.

Latimer, R.N.C. and Martin, R.V. (2019). Interpretation of measured aerosol mass scattering efficiency over North America using a chemical transport model. Atmos. Chem. Phys. 19: 2635-2653.

Liu, H., He, K., Lents, J.M., Wang, Q. and Tolvett, S. (2009). Characteristics of diesel truck emission in China based on portable emissions measurement systems. Environ. Sci. Technol. 43: 9507-9511.

Mahapatra, P.S., Puppala, S.P., Adhikary, B., Shrestha, K.L., Dawadi, D.P., Paudel, S.P. and Panday, A.K. (2019). Air quality trends of the Kathmandu Valley: A satellite, observation and modeling perspective. Atmos. Environ. 201: 334-347.

Maji, S., Ahmed, S. and Siddiqui, W.A. (2015). Air quality assessment and its relation to potential health impacts in Delhi, India. Curr. Sci. 109: 902-909.

Manufacturers of Emission Controls Association (2014). Emission control of two- and three-wheel vehicles, http://www.meca.org/resources/Motorcycle_whitepaper _update_0914.pdf, Last Access: 7 March 2019.

McCormick, R.L., Graboski, M.S., Alleman, T.L. and Yanowitz, J. (2000). Idle emissions from heavy-duty diesel and natural gas vehicles at high altitude. J. Air Waste Manage. Assoc. 50: 1992-1998.

McCormick, R.L., Graboski, M.S., Alleman, T.L., Alvarez, J.R. and Duleep, K.G. (2003). Quantifying the emission benefits of opacity testing and repair of heavy-duty diesel vehicles. Environ. Sci. Technol. 37: 630-637.

Molina, M.J. and Molina, L.T. (2004). Megacities and atmospheric pollution. J. Air Waste Manage. Assoc. 54: 644-680.

Moosmuller, H., Mazzoleni, C., Barber, P.W., Kuhns, H.D., Keislar, R.E. and Watson, J.G. (2003). On-road 
measurement of automotive particle emissions by ultraviolet lidar and transmissometer: Instrument. Environ. Sci. Technol. 37: 4971-4978.

Mountain Air Engineering (2016). Ratnoze1 user guide, http://www.mtnaireng.com/Ratnoze1_User_Guide_v8.p df, Last Access: 7 March 2019.

Mues, A., Lauer, A., Lupascu, A., Rupakheti, M., Kuik, F. and Lawrence, M.G. (2018). WRF and WRF-Chem v3. 5.1 simulations of meteorology and black carbon concentrations in the Kathmandu Valley. Geosci. Model Dev. 11: 2067-2091.

Njoku, K.L., Rumide, T.J., Akinola, M.O., Adesuyi, A.A. and Jolaoso, A.O. (2016). Ambient air quality monitoring in metropolitan city of Lagos, Nigeria. J. Appl. Sci. Environ. Manage. 20: 178-185.

Parajuly, K. (2016). Pollution: Clean up the air in Kathmandu. Nature 533: 321.

Park, S.S., Kozawa, K., Fruin, S., Mara, S., Hsu, Y.K., Jakober, C., Winer, A. and Herner, J. (2011). Emission factors for high-emitting vehicles based on on-road measurements of individual vehicle exhaust with a mobile measurement platform. J. Air Waste Manage. Assoc. 61: 1046-1056.

Petkova, E.P., Jack, D.W., Volavka-Close, N.H. and Kinney, P.L. (2013). Particulate matter pollution in African cities. Air Qual. Atmos. Health 6: 603-614.

Sahu, S.K. and Kota, S.H. (2017). Significance of $\mathrm{PM}_{2.5}$ air quality at the Indian capital. Aerosol Air Qual. Res. 17: 588-597.

Sarkar, C., Sinha, V., Sinha, B., Panday, A.K., Rupakheti, M. and Lawrence, M.G. (2017). Source apportionment of NMVOCs in the Kathmandu Valley during the SusKat$\mathrm{ABC}$ international field campaign using positive matrix factorization. Atmos. Chem. Phys. 17: 8129-8156.

Schneider, J., Kirchner, U., Borrmann, S., Vogt, R. and Scheer, V. (2008). In situ measurements of particle number concentration, chemically resolved size distributions and black carbon content of traffic-related emissions on German motorways, rural roads and in city traffic. Atmos. Environ. 42: 4257-4268.

Shakya, K.M., Rupakheti, M., Shahi, A., Maskey, R., Pradhan, B., Panday, A., Puppala, S.P., Lawrence, M. and Peltier, R.E. (2017). Near-road sampling of $\mathrm{PM}_{2.5}$, BC, and fine-particle chemical components in Kathmandu Valley, Nepal. Atmos. Chem. Phys. 17: 6503-6516.

Sharma, R.K., Bhattarai, B.K., Sapkota, B.K., Gewali, M.B. and Kjeldstad, B. (2012). Black carbon aerosols variation in Kathmandu Valley, Nepal. Atmos. Environ. 63: 282288.

Shrestha, R.M. and Malla, S. (1996). Air pollution from energy use in a developing country city: The case of Kathmandu Valley, Nepal. Energy 21: 785-794.
Shrestha, S.R., Kim Oanh, N.T., Xu, Q., Rupakheti, M. and Lawrence, M.G. (2013). Analysis of the vehicle fleet in the Kathmandu Valley for estimation of environment and climate co-benefits of technology intrusions. Atmos. Environ. 81: 579-590.

Stockwell, C.E., Christian, T.J., Goetz, J.D., Jayarathne, T., Bhave, P.V., Praveen, P.S., Adhikari, S., Maharjan, R., DeCarlo, P.F., Stone, E.A., Saikawa, E., Blake, D.R., Simpson, I.J., Yokelson, R.J. and Panday, A.K. (2016). Nepal Ambient Monitoring and Source Testing Experiment (NAMaSTE): Emissions of trace gases and light-absorbing carbon from wood and dung cooking fires, garbage and crop residue burning, brick kilns, and other sources. Atmos. Chem. Phys. 16: 11043-11081.

Stone, E.A., Schauer, J.J., Pradhan, B.B., Dangol, P.M., Habib, G., Venkataraman, C. and Ramanathan, V. (2010). Characterization of emissions from South Asian biofuels and application to source apportionment of carbonaceous aerosol in the Himalayas. J. Geophys. Res. 115: D06301.

Stone, E.A., Nguyen, T.T., Pradhan, B.B. and Dangol, P.M. (2012). Assessment of biogenic secondary organic aerosol in the Himalayas. Environ. Chem. 9: 263-272.

Subramanian, R., Winijkul, E., Bond, T.C., Thiansathit, W., Oanh, N.T.K., Paw-Armart, I. and Duleep, K.G. (2009). Climate-relevant properties of diesel particulate emissions: Results from a piggyback study in Bangkok, Thailand. Environ. Sci. Technol. 43: 4213-4218.

Wang, H., Ge, Y., Tan, J., Wu, L., Wu, P., Hao, L., Peng, Z., Zhang, C., Wang, X., Han, Y. and Zhang, M. (2018). The real-world emissions from urban freight trucks in Beijing. Aerosol Air Qual. Res. 18: 1448-1456.

Wang, J.F., Hu, M.G., Xu, C.D., Christakos, G. and Zhao, Y. (2013). Estimation of citywide air pollution in Beijing. PLoS One 8: e53400 (1-6).

Wang, X., Westerdahl, D., Wu, Y., Pan, X. and Zhang, K.M. (2011). On-road emission factor distributions of individual diesel vehicles in and around Beijing, China. Atmos. Environ. 45: 503-513.

Weingartner, E., Keller, C., Stahel, W.A., Burtscher, H. and Baltensperger, U. (1997). Aerosol emission in a road tunnel. Atmos. Environ. 31: 451-462.

Zhang, Y., Stedman, D.H., Bishop, G.A., Guenther, P.L. and Beaton, S.P. (1995). Worldwide on-road vehicle exhaust emissions study by remote sensing. Environ. Sci. Technol. 29: 2286-2294.

Received for review, June 10, 2019 Revised, September 1, 2019 Accepted, September 6, 2019 